\title{
Preparing research on optimized construction of sustainable human living environment in regions where people of a certain ethnic group live in compact communities in China
}

\author{
Junyan Dong ${ }^{1,2,3,{ }^{*}}$ and Wen Cheng ${ }^{1}$ \\ ${ }^{1}$ School of Architecture, Harbin Institute of Technology, Harbin, China \\ 2 School of Architecture and Design, Changchun Institute of Technology, Changchun, China \\ ${ }^{3}$ International Asia Art Academy, Bangkok Thonburi University, Bangkok, Thailand
}

\begin{abstract}
Due to the poor transport system, remoteness and few channels to access to information from the outside world in most minority-inhabited areas in China, buildings in these areas are well preserved. In particular, dwellings in these places show low-tech and ecological features. Different types and the natural environment of the plateau where Shangri-La lies provide people with a variety of living resources. As living environments vary in different areas, different inhabitation forms have been formed. Tibetan people adjust measures to local conditions and excel at using local materials and appropriate technologies to build houses. In this paper, a case study is made of traditional dwellings in Tibetan-inhabited areas in Shangri-La, to analyze lowtech and ecological strategies for traditional dwellings in Tibetan-inhabited areas in Shangri-La, from three aspects: regional environment measures, building technologies and the spatial order system.
\end{abstract}

\section{Overview of traditional dwellings in Shangri-La}

Due to the poor transport system, remoteness and few channels to access to information from the outside world in most minority-inhabited areas in China, buildings in these areas are well preserved. In particular, dwellings in these places show low-tech and ecological features. Different types and the natural environment of the plateau where Shangri-La lies provide people with a variety of living resources. As living environments vary in different areas, different inhabitation forms have been formed. Tibetan people adjust measures to local conditions and excel at using local materials and appropriate technologies to build houses. In this paper, a case study is made of traditional dwellings in Tibetan-inhabited areas in Shangri-La, to analyze low-tech and ecological strategies for traditional dwellings in Tibetan-inhabited areas in Shangri-La, from three aspects: regional environment measures, building technologies and the spatial order system [1].

The Tibetan Ethnic Group which originates in QinghaiTibet Plateau is distributed in the regions at an altitude of $2000-3500 \mathrm{~m}$ and above. The Tibetan Ethnic Group is honored as snowy ethnic group because its people have been living in a snowy plateau. With a long history and developed culture, Tibetan Ethnic Group is mainly distributed in the Chinese regions such as Tibet Autonomous

\footnotetext{
* e-mail: djyrob@gmail.com
}

Region, the south of Gansu Province, Sichuan and the Qinghai-Tibet Plateau in the northwest of Yunnan. ShangriLa Tibetan Ethnic Group mainly inhabits Diqing Tibetan Autonomous Prefecture in the southern extension of Qinghai-Tibet Plateau-a part of Hengduan Mountains as well as in the northwest of the junction among Yunnan, Tibet and Sichuan.

Shangri-La Tibetan Ethnic Group is distributed in three types of regions: alpine region at an altitude of 2800 and above, hot-dry valley region at an attitude of 2000-2800 and the semi-mountainous and valley regions also inhabited by other ethnic groups. As the major settlements of Shangri-La Tibetan Ethnic Group, alpine region and hot-dry valley region are filled with the representative Tibetan dwellings of Shangri-La. These two types of regions show distinctive regional environmental characteristics because residents in different regions rely on different production and living modes, and inhabitation forms. The alpine region is characterized by vast territory and flat terrain, where Tibetan people resort to the production mode that combines livestock raising with farming together - the semisedentary and semi-nomadic mode, and the dwellings are built in a scattered way, such as Hongpo Village, Jiantan Town (Fig. 1). By comparison, the hot-dry valley regions are equipped with complicated terrains and situated near the mountains and by the rivers; Tibetan people tend to settle down in this region, where the production mode mainly consists of farming, planting and collection, and the dwellings are primarily established in tablelands, such as Yuejin Village, Dongwang Township (Fig. 2). 

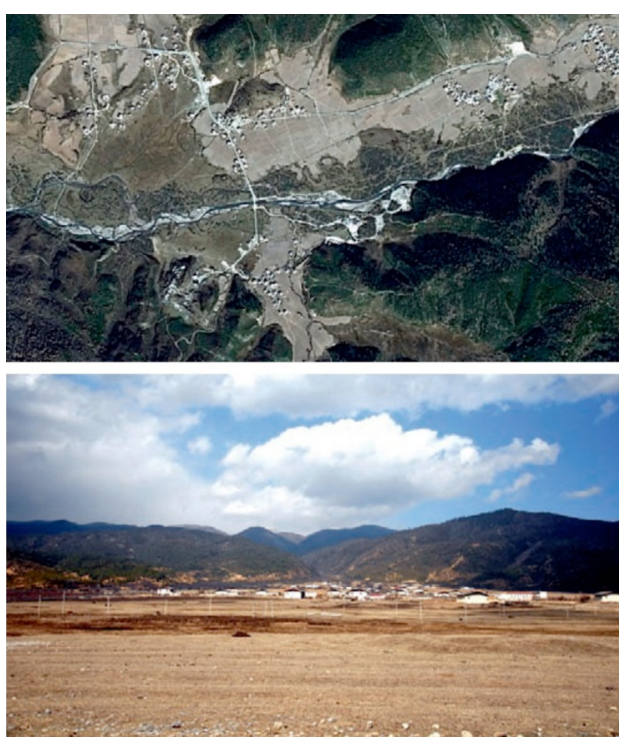

Fig. 1. Hongpo Village, Jiantan Town.
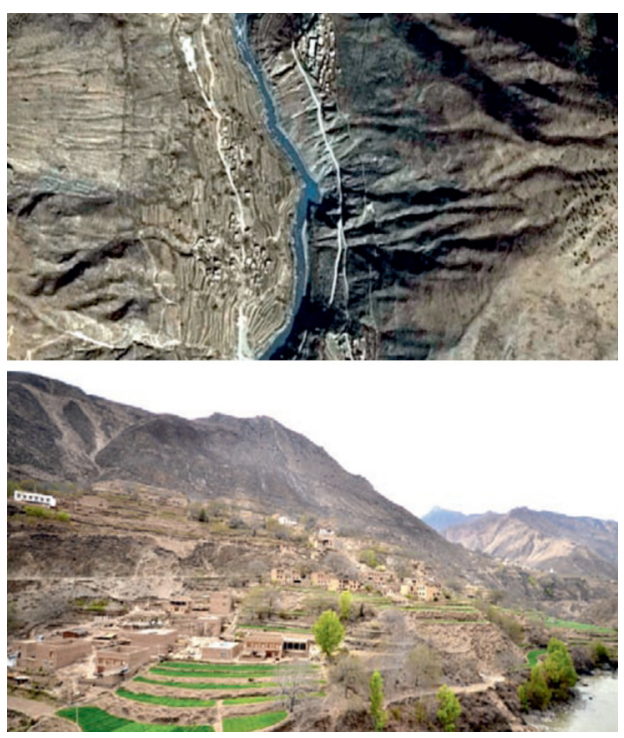

Fig. 2. Yuejin Village, Dongwang Township.

With an annual average temperature of $5^{\circ} \mathrm{C}$, Hongpo Village, Jiantan Town at an altitude of $3300 \mathrm{~m}$ is a typical settlement village in alpine regions. Local Tibetan people grow the alpine plants such as highland barley and potation in the flat alpine regions nearby and meanwhile raise the domestic animals in broad alpine grassland. Farmers and herders tend to make use of the semisedentary and seminomadic mode: they graze domestic animals in the grassland when there is a mild climate and the river valley is full of life, whereas in the cold Winter, they return home to continue with their production. Under this circumstance, the semi-farming and semi-husbandry mode peculiar to Shangri-La Tibetan Ethnic Group in the alpine regions takes shape. Due to the peculiar external environment and production and living modes, the village features a scattered layout in which several households constitute a group and several groups constitute a block in the flat alpine grassland. With an annual average temperature of $15^{\circ} \mathrm{C}$, Yuejin Village, Dongwang Township at an altitude of $2700 \mathrm{~m}$ is the typical representative of hotdry valley region. In consideration of limited land, local Tibetan people establish villages in a small size and dwellings are largely distributed in tablelands. The gentle slopes by the rivers in different villages are used for farming, and the dwellings are mainly established in the steep regions at a high altitude. Considering that the rainless hot-dry valley enjoys a dry climate, Tibetan people grow the economic crops like wheat, corn and walnut, rear the domestic animals in captivity and collect the plants such as pine mushroom and aweto [2].

The difference in village layouts and architectural distribution characteristics results from the difference in external regional environments (Tab. 1). In consideration of different regional conditions, Tibetan people make full use of external natural conditions to meet production and living needs intelligently, and different village layouts have taken shape in different regions after long-term development.

\section{Regional environmental measures}

Given the special highland climate, Tibetan residents in Shangri-La have accumulated a lot of experience to create simple ecology on the basis of seeking advantages and avoid disadvantages. Different village layout patterns and building distribution features have been formed in different external regional environment, to respond to different Regional conditions. The Tibetan people wisely take advantage of their natural conditions to meet production and living needs. Over time, different village layout patterns and building construction modes have been formed in these areas. Traditional Tibetan dwellings are mainly designed to face sun and avoid wind. Their living space is usually quite small, while the kitchen is taken as the main use space to realize "living around the fire". Moreover, curtains are hanged inside doors to reduce the loss of indoor heat. Canvas is used for sunshade so as to reduce solar radiation from the outdoor. Traditional Tibetan dwellings are also a carrier of the traditional Tibetan culture. Unique architecture forms and component parts of traditional Tibetan dwellings also imply corresponding regional culture meanings [3].

\subsection{Heat loss control}

Since Shangri-La is situated in cold regions, the focus of Shangri-La dwellings is to keep warm in Winter. Given that indoor fireplace is the most common heating mode, the key is to maintain indoor thermal comfort by controlling building's heat loss. Traditional Shangri-La dwellings tend to control heat loss from three aspects as follows:

- Shape and functional layout

Traditional Shangri-La dwellings are usually built in a compact and simple shape with a view to reducing heat dissipation area of building's exterior surface as well as the heat exchange between indoors and outdoors in Winter. The surface is largely constituted by squareshaped patterns, such as the shapes of the Chinese characters “回”, “曰”, and “口”, and partly by "L" 
Table 1. Comparison between two villages in different regions.

\begin{tabular}{lll}
\hline & Hongpo Village, Jiantan Town & Yuejin Village, Dongwang Township \\
\hline Regional characteristics & Alpine region & Semi-mountainous hot-dry valley region \\
Altitude & $3300 \mathrm{~m}$ & $2700 \mathrm{~m}$ \\
Annual average temperature & $5^{\circ} \mathrm{C}$ & $15^{\circ} \mathrm{C}$ \\
Production and living modes & Farming, livestock raising & Farming, planting, collection \\
Village type & Group-based scattered type & Semi-mountainous centralized type \\
\hline
\end{tabular}

shaped patterns. In terms of facade, the dwellings have the same height at both the left and the right sides, and besides, they are symmetrically built as bungalows in a majority; the small number of aristocratic mansions are only equipped with two or three floors, and few with four floors. For the sake of a small building volume, the floor $2.2-2.6 \mathrm{~m}$ in height is designed; the column distance is small, only arriving at $2-2.2 \mathrm{~m}$, and the height of a twofloor building is usually controlled within $5 \mathrm{~m}$; small height can reduce indoor air flow velocity to control indoor temperature. In respect of function, kitchen is used most frequently as space with fireplace, in which the indoor thermal environment is comfortable; therefore, kitchen also has the function of living room that is usually used to receive visitors. In general, Kitchen is situated at one side of a building and near the door for the purpose of ensuring the convenience for external connections. The storage room is located in the north close to the living room. The compact and reduced layout has controlled the size effectively to a great extent, which has created favorable conditions for the reduction of the heat exchange with outdoor environment [4].

- Building envelop openings

Aside from the day-lighting window in the south facing the sun, no window or only a small window aperture will be designed in the north of dwellings in order to reduce heat dissipation through window, regulate air ventilation and decrease heat loss. The heavy door leaf and portiere can stop the wind and keep warm in windy and cold weather. Both window size and windowsill height are small, which can ensure heat preservation and sufficient light. In the daytime, the window in the south can gather solar energy as much as possible, and in the nighttime, the heavy, thick and course pulu curtain can lessen indoor heat dissipation as a thermal barrier.

- Heavy and thick external building envelope

In many cases, residential building structural systems are exteriorly equipped with stone walls or the loadbearing walls like rammed earth wall, and interiorly with beam and column framework. This structural system can be regarded as a tool of tackling the extremely hostile weather. The traditional Shangri-La building shows following characteristics: the exterior wall is heavy, thick and built by contracture technique, and the heavy and thick walls are utilized to increase room's nighttime temperature and average temperature because of its coldproof and heat preservation functions. The building is made of thick rubble wall and rammed earth wall, with the thickness ranging from 0.4 to $0.7 \mathrm{~m}$. For special buildings, however, the thickness of external wall even arrives at $1 \mathrm{~m}$. On the one hand, the wall can minimize indoor heat conduction and dispassion due to the huge thermal resistance, and on the other, the thick and heavy wall can stabilize the fluctuation of indoor temperature and maintain thermal stability during indoor intermittent heating because of the high thermal storage capacity. With reference to color, the interior wall is decorated with warm colors such as earthly yellow and red. Additionally, the materials that can create a sense of warmth, such as timber and coarse stone, are used to provide the psychological warm for people in a cold environment.

\subsection{Rain-proof and damp-proof functions}

In the regions equipped with flat-roofed dwellings, the annual rainfall is low but the rainy season is concentrated and the clay has low water-resistant ability. In consideration of this, building envelope shall be specially processed in order to avoid rain erosion. Traditional building is mainly covered with the aga clay flat roof. The structure is mainly comprised of three layers, with the first layer constituted by load-bearing timbers like rafter; the second by ordinary adobes as a connection layer; and the third by roof covering. The third layer is the impervious aga clay layer that is rammed and polished with oil; because of low water permeability, the aga clay layer has high rain-proof capacity, thus applying to the rainless and dry regions. In many cases, the dwellings are exteriorly armed with rubble walls; the adobe or the clay of stone wall will be furnished with a rainbow-shaped pattern drawn by five figures, which can not only contribute to creating a sense of beauty, but also preventing the adobe from being washed away by rain. A majority of residents equip parapets with the pancakeshaped dung or square-shaped grassland, which can produce remarkable waterproof effects in rainy season as a result of high water absorption ability. Some residents furnish architrave cornices with blue flagstones so that the rain will fall along the blue flagstones in Summer without permeating the wall. Additionally, the blue flagstones are also established in footpaths or the wall corners of buildings for the sake of water drainage [5].

\subsection{Obstruction and utilization of solar radiation}

Solar radiation on the one hand is indispensable for the alpine regions of Shangri-La, but on the other is harmful to human health due to its strong ultraviolet ray. Therefore, the intense solar radiation should be utilized and prevented in a proper way. For instance, in order to prevent solar 


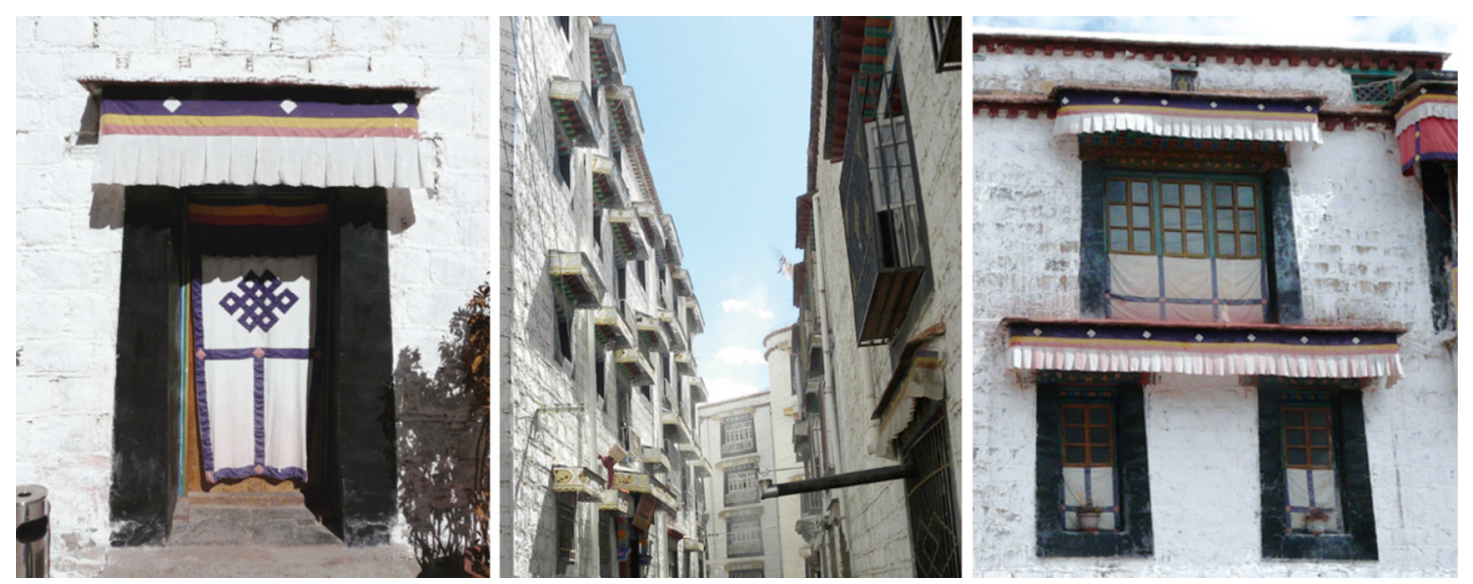

Fig. 3. Traditional dwellings sunshade in Tibetan-inhabited areas in Shangri-La.

radiation, highland people tend to wear hats, mask and scarf all the year round. The buildings there are equipped with large numbers of solid walls but small numbers of window apertures. In terms of color, the exterior wall is largely colored in white, which can reflect the intense solar radiation; the window framework is black, which therefore can absorb the solar radiation to raise the air temperature of window aperture in the cold weather. Additionally, most of Shangri-La's dwellings equip the windows in the south with sunshades in an attempt to prevent the intense solar radiation. The radiation has not only a tremendous effect on indoor temperature balance, but also a severe impact on buildings, especially the exposed timbers, windows, doors and the colored drawings on their surfaces. Therefore, compared with other cold regions, it is highly necessary for Shangri-La to take account of sunshade (Fig. 3).

For rural dwellings in Shangri-La, dung is dried as fuels on wall surface or the brick-shaped dung is stacked on roof's parapets. The dung which can be dried as heating fuels by solar radiation can also reduce the weight of wall and reinforce the wall.

\subsection{Interior spatial plane of typical dwellings}

The most important spaces of Shangri-La's dwellings are kitchen and the semi-open living room mainly intended for family activities.

- Kitchen is the important space of family activities in traditional Shangri-La dwellings compared with other regions. Due to the low temperature in Winter, bonfire or fireplace is used to boil water or cook meals in kitchen both in the morning and evening. Therefore, indoor temperature of kitchen is always high. In consideration of this, kitchen is utilized for family activities in the evening as a substitute for living room in traditional sense. Kitchen is not only used for cooking purpose, but also taken as the space of family activities. Meanwhile, because of the large thickness, the wall of traditional dwellings achieves high thermal-resistant performance and thermal storage performance. Therefore, when the fireplace is used, the heat loss of external building envelope can be reduced and the heat can be stored as well; when the fireplace stops working in the nighttime, the wall can slow the decline in internal temperature by means of heat release.
- Semi-open living room is a special internal space in the alpine regions of Shangri-La intended for family activities in Winter daytime. The south of the semi-open living room is open, which can help to absorb most solar radiation in Winter, with the remaining three sides serving as an envelope structure.

Pit toilet is another special space required by rural dwellings in the alpine regions of Shangri-La. At the end of fall, the weather is usually cold in many places. Therefore, in order to avoid the frozen fertilizer that cannot be excavated, pit toilet tends to be built in the regions exposed to sun for the purpose of increasing fertilizer temperature.

\section{Building technologies}

The building modes and ways of dwellings vary with regional environments and village layouts. In alpine regions, Tibetan dwellings are largely equipped with two slopes and wood block tile, and the architectural technical element is to keep warm; in hot-dry valley regions, Tibetan dwellings are mainly the earthen blockhouses with the flat roof made of rammed earth, and the architectural technical element is to guarantee ventilation and heat dissipation. An analysis shows that the utilization of materials, structures and spatial form of Tibetan dwellings in Shangri-La is fully considered based on ecological lowtech strategies. Below is the comparative analysis on the Tibetan dwellings in two different regional environments.

For instance, in alpine region, the typical Tibetan architecture is Sun Nuo's dwelling in Hongpo Village, Jiantan Town (Fig. 4).

Hongpo Village is a local tourism village of Tibetan Cultural Ecology, where majorities of dwellings are well preserved. Despite having been rebuilt, Sun Nuo's dwelling is still kept in good condition as a typical dwelling of Shangri-La's Tibetan Ethnic Group in alpine region. In the external regional environment with an altitude of $3300 \mathrm{~m}$ and an annual average temperature of $5{ }^{\circ} \mathrm{C}$, the traditional Tibetan dwellings are built with raw soil materials and timbers that have high heat preservation ability. These dwellings are equipped with a 2.5 -floor earthen and wooden structure, a wide veranda at one side, two slopes, and wood block tile. When building private houses, villagers will 

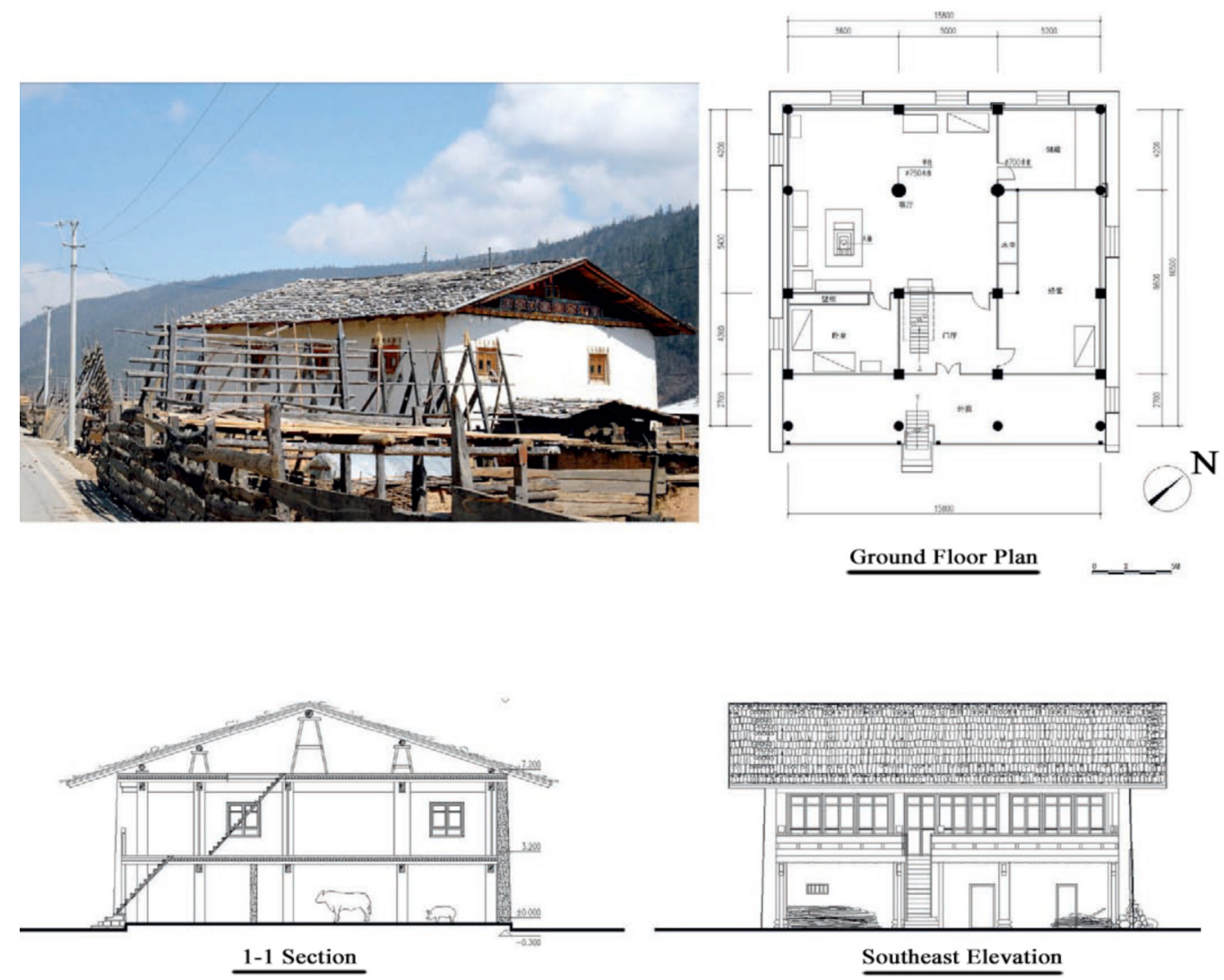

Fig. 4. Sun Nuo's dwelling in Hongpo Village, Jiantan Town.

come to help each other. As regards the function of each floor, the first floor is used for livestock raising; the second floor for family activities; and the top interlayer with high floor height for storage.

In hot-dry valley region, for instance, the typical Tibetan dwelling is Lurong Nima's dwelling in Yuejin Village, Dongwang Township (Fig. 5).

As migrant workers, its family members neglect updating the dwelling. In Yuejin Village, this dwelling is best preserved in terms of traditional style. In the external regional environment with an altitude of $2700 \mathrm{~m}$ and an annual average temperature of $15^{\circ} \mathrm{C}$, Tibetan dwellings resort to different building materials and techniques compared with those in alpine regions, whereas these two types of dwellings share some similarities as well. This dwelling is equipped with a 3 -floor earthen and wooden structure, and flat roof. When building private houses, villagers will come to help each other. As the major building material with good thermal performance, raw soil can be obtained locally; timbers are the building materials widely applied to China's traditional dwellings. With reference to the function of each floor, the first floor is designed to raise livestock; the second floor to serve family life; and the third floor as scripture hall and semi-open storage space. The technical elements of this dwelling are listed in Table 2.

In combination with the analysis on the two cases, this paper performs a comparative study on the architectural technical elements of Tibetan dwellings in alpine region and hot-dry valley region. Tibetan dwellings with different regional environments in Shangri-La greatly vary in their forms and space. However, to adapt to external regional conditions, ecological and low-tech strategies are employed for building Tibetan dwellings in Shangri-La. To be specific, locally produced materials and appropriate technologies are used for building Tibetan dwellings. Proper building types are chosen when different materials are used. Outdoor and indoor space is rationally arranged. Details are seriously treated in building dwellings. Traditional local house-building methods are used and mutual assistance is provided in building dwellings. Meanwhile, key consideration should be given to control of heat loss, protection against rain and moisture, use and prevention of solar radiation and other aspects. Combined with local actual conditions, this kind of house-building logic and techniques is easy to learn and put into practice, reflecting the economic and scientific ecological and lowtech strategies for building Tibetan dwellings.

\section{Space order system}

In areas with different regional environment, building techniques are different. As a result, distinctive architectural forms and spatial systems are formed for Tibetan dwellings in Shangri-La. However, they also share some sameness or similarities, that is, "Tibetan residential space logic" including both the horizontal and vertical spatial order. According to the architectural plane of the Tibetan dwelling in the alpine region, the core space constituted by the main hall with center pillar and scripture hall is the 

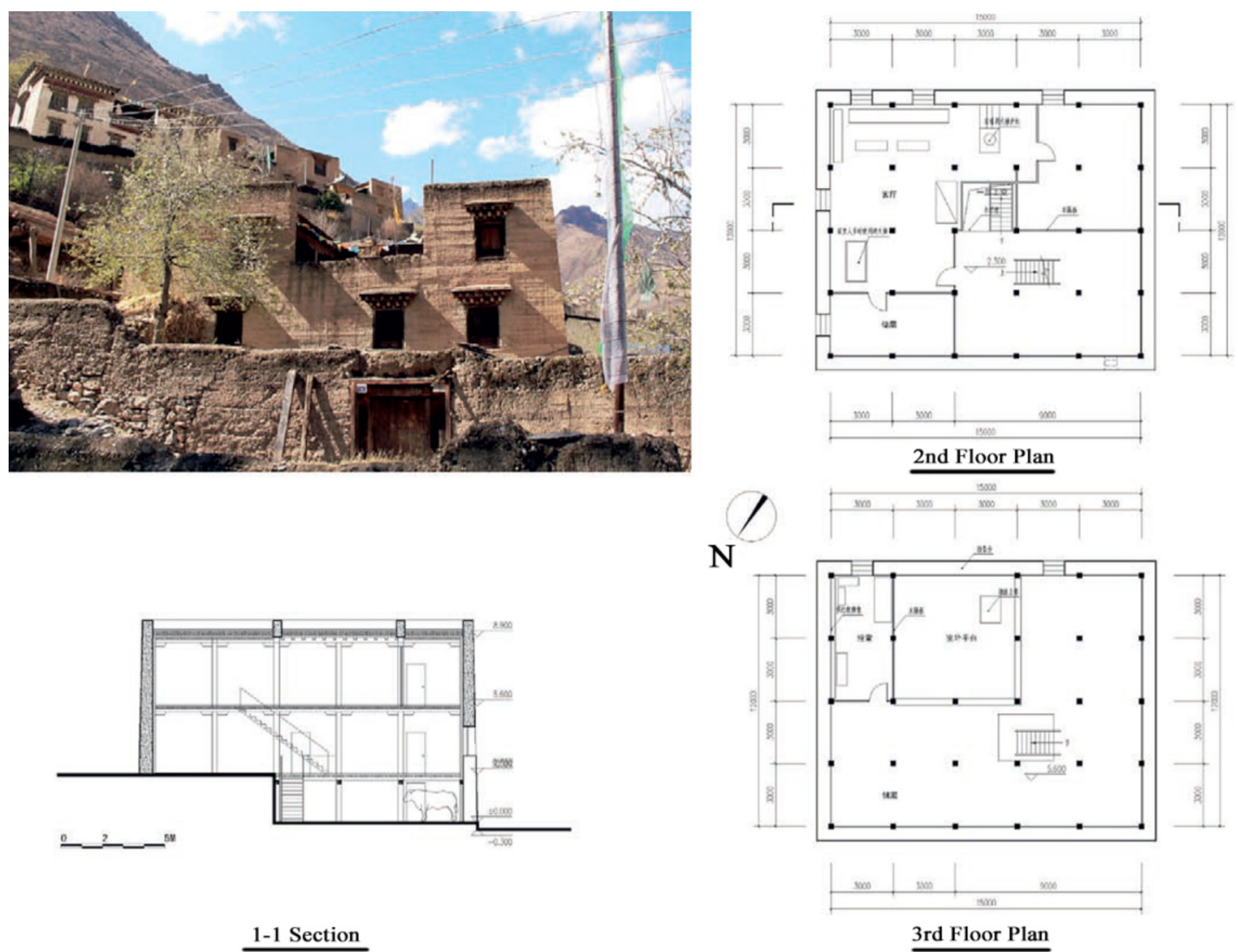

Fig. 5. Lurong Nima's dwelling in Yuejin Village, Dongwang Township.

Table 2. Technological factors in building traditional Tibetan dwellings in Shangri-La.

\begin{tabular}{|c|c|c|}
\hline Building techniques & Using functions & $\begin{array}{l}\text { Architectural forms and space } \\
\text { performance }\end{array}$ \\
\hline $\begin{array}{l}\text { Thick rammed earth as the } \\
\text { outer wall }\end{array}$ & $\begin{array}{l}\text { Traditional building materials with } \\
\text { good thermal performance }\end{array}$ & $\begin{array}{l}\text { The wall thickness is reduced from } \\
\text { bottom to top, forming a "T" battered } \\
\text { shape. }\end{array}$ \\
\hline $\begin{array}{l}\text { Three-layer soil-and-wood } \\
\text { structure }\end{array}$ & $\begin{array}{l}\text { Atria are designed for ventilation } \\
\text { and heat dissipation. }\end{array}$ & $\begin{array}{l}\text { The bottom layer for raising livestock; } \\
\text { the medium layer for living; the upper } \\
\text { layer for scripture hall and storage }\end{array}$ \\
\hline Semi-open attic floor & Ventilation and heat dissipation & $\begin{array}{l}\text { Indoor and outdoor spatial switching } \\
\text { and connection }\end{array}$ \\
\hline $\begin{array}{l}\text { Large window and door } \\
\text { openings }\end{array}$ & Ventilation and heat dissipation & $\begin{array}{l}\text { Door and window shapes and } \\
\text { decorative of traditional Tibetan } \\
\text { dwellings }\end{array}$ \\
\hline Flat rammed-earth roof & For dying grain and roofing activities & Flattened form \\
\hline
\end{tabular}

central functional area of the dwelling, with other functional rooms established around the core space. In the Tibetan dwelling of the hot-dry valley region, each floor has its unique function: the first floor is used to raise livestock; the second floor to serve family life; and the third floor as the sculpture hall. This has embodied the religious logical thinking of deity supremacy. Both the two spaces have shown the ethnic characteristics of Tibetan Ethnic Group, and the interior and exterior space is reasonably arranged under the guidance of religious belief and traditional ethnic culture. Meanwhile, the embodiment of ethnic characteristics in building has increased the artistry and decorativeness of building space and structural materials, and distinctive ethnic characteristics have taken shape, such as center pillar in main hall, fireplace, pavilion, scripture hall, and decorative arts of doors and windows. While controlling the architectural space and form of Tibetan dwellings in Shangri-La, the horizontal and vertical spatial order also implies the low-tech and ecological logic at different levels. According to the 

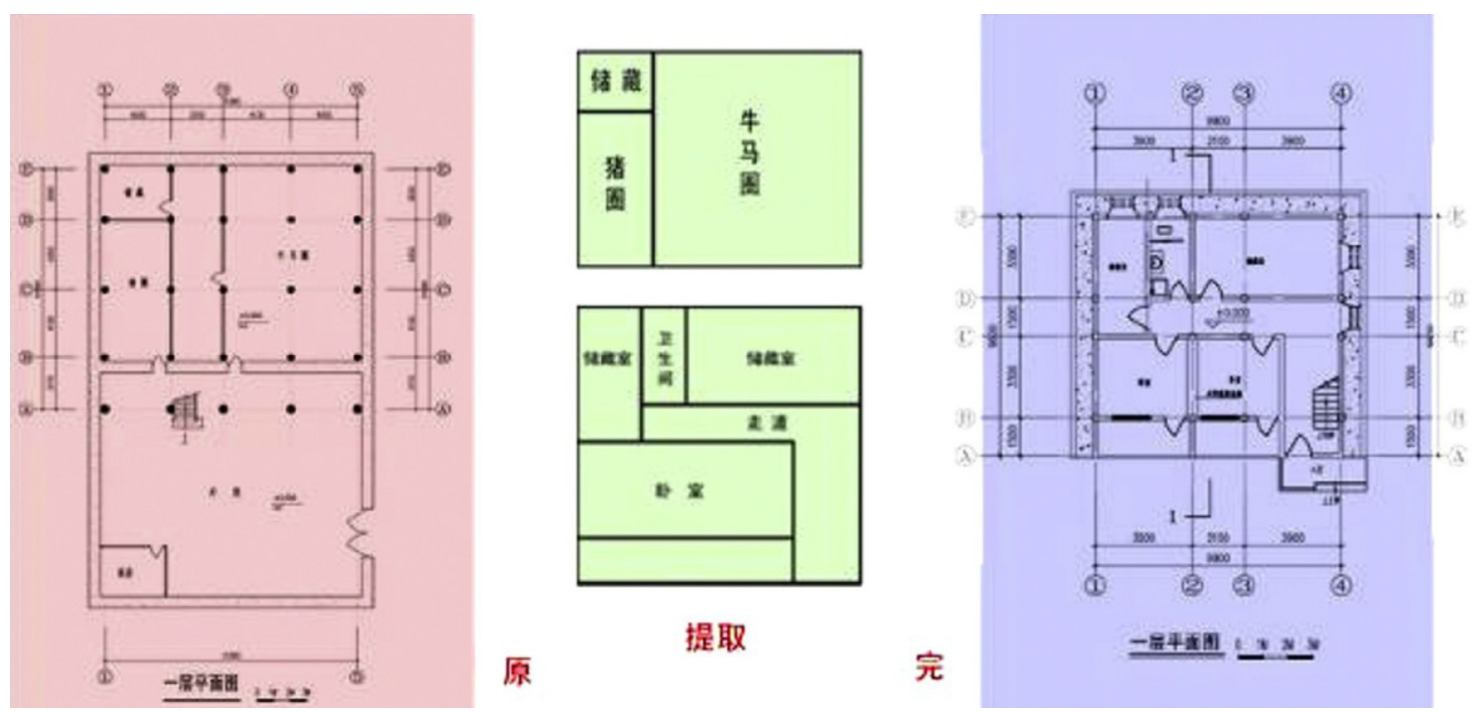

Fig. 6. Reconstruction examples.

horizontal order, secondary rooms centre on main rooms; private space centers on public space; core space becomes the horizontal core of houses, so as to strive to be compact, economic and efficient. According to the vertical spatial order, draught animals are reared in the bottom space. In this way, it not only facilitates the feed, but also makes full use of indoor thermal environment, thus meeting the temperature requirement in the bottom space and realizing ecological energy saving (Fig. 6).

\section{Conclusions}

Traditional Tibetan dwellings which have a unique climatic and geographical environment as well as distinctive ethnic culture are influenced by religious relief and folk customs. After long-term development and evolution, there emerges a special architectural form and a building image that is a symbol of religious culture. The analysis on the building strategies and cultural meanings of traditional Tibetan dwellings can lay a foundation for continuing the history of traditional Tibetan buildings as well as inheriting and improving traditional Tibetan buildings. Regional environmental measures, building techniques and spatial order system are ecological and low-tech logic and strategies that have come down in one continuous line in building Tibetan dwellings in Shangri-La. In the hierarchy composed of "region-building-space and details", Tibetan residents in Shangri-La adjust measures to local regional environments, use local materials and choose appropriate house-building techniques to build their houses. Local craftsmen use traditional house-building techniques and mutual assistance is provided in house building. All of these reflect the low-tech and ecological thinking and excellent and simple ecological low-tech strategies, with great values in providing lessons and reference to build houses for lowincome people which account for the majority in China.

This study was funded by the National Science \& Technology Pillar Program during the Twelfth Five-year Plan Period of China (No. 2013BAJ12B01) and Science and Technology Project Foundation of Ministry of Housing and Urban-Rural Construction of the People's Republic of China (No. 2016R2005) and Youth Foundation of Changchun Institute of Technology (No. 320140006) and Jilin Provincial Social Science Foundation (No. 120150065).

\section{References}

1. J. Dong, H. Jin, The design strategy of green rural housing of Tibetan areas in Yunnan, China, Renew. Energy 49, 63 (2013)

2. J. Dong, W. Cheng, Based on the characteristics of respondents and the voice of the urban neighborhood public space business facilities noise environment evaluation research, J. Harbin Inst. Technol. 20, 103 (2014)

3. J. Dong, H. Jin, J. Kang, X. Chen, A pilot study of the acoustic environment in residential areas in Harbin, towards the questionnaire design, J. Harbin Inst. Technol. 18, 319 (2011)

4. D. Junyan, J. Hong, K. Jian, W. Liying, H. Qiushi, Research on the evaluation of the traffic acoustic environment in public space of residential community based on the characteristics of residents, Archit. J. 10, 124 (2013)

5. D. Junyan, J. Hong, K. Jian, Research of acoustic environment in public space in urban residential community in China, Huazhong Archit. 30, 61 (2012)

Cite this article as: Junyan Dong, Wen Cheng, Preparing research on optimized construction of sustainable human living environment in regions where people of a certain ethnic group live in compact communities in China, Renew. Energy Environ. Sustain. 1, 40 (2016) 